\title{
Expertise under the microscope: processing histopathological slides
}

Citation for published version (APA):

Jaarsma, T., Jarodzka, H., Nap, M., van Merrienboer, J. J. G., \& Boshuizen, H. P. A. (2014). Expertise under the microscope: processing histopathological slides. Medical Education, 48(3), 292-300. https://doi.org/10.1111/medu.12385

Document status and date:

Published: 01/03/2014

DOI:

10.1111/medu.12385

Document Version:

Publisher's PDF, also known as Version of record

Document license:

Taverne

\section{Please check the document version of this publication:}

- A submitted manuscript is the version of the article upon submission and before peer-review. There can be important differences between the submitted version and the official published version of record.

People interested in the research are advised to contact the author for the final version of the publication, or visit the DOI to the publisher's website.

- The final author version and the galley proof are versions of the publication after peer review.

- The final published version features the final layout of the paper including the volume, issue and page numbers.

Link to publication

\footnotetext{
General rights rights.

- You may freely distribute the URL identifying the publication in the public portal. please follow below link for the End User Agreement:

www.umlib.nl/taverne-license

Take down policy

If you believe that this document breaches copyright please contact us at:

repository@maastrichtuniversity.nl

providing details and we will investigate your claim.
}

Copyright and moral rights for the publications made accessible in the public portal are retained by the authors and/or other copyright owners and it is a condition of accessing publications that users recognise and abide by the legal requirements associated with these

- Users may download and print one copy of any publication from the public portal for the purpose of private study or research.

- You may not further distribute the material or use it for any profit-making activity or commercial gain

If the publication is distributed under the terms of Article $25 \mathrm{fa}$ of the Dutch Copyright Act, indicated by the "Taverne" license above, 


\section{Expertise under the microscope: processing histopathological slides}

Thomas Jaarsma, ${ }^{1}$ Halszka Jarodzka, ${ }^{1}$ Marius Nap, ${ }^{2}$ Jeroen J G van Merrienboer ${ }^{1,3}$ \& Henny P A Boshuizen ${ }^{1}$

OBJECTIVES Although the obvious goal of training in clinical pathology is to bring forth capable diagnosticians, developmental stages and their characteristics are unknown. This study therefore aims to find expertise-related differences in the processing of histopathological slides using a combination of eye tracking data and verbal data.

METHODS Participants in this study were 13 clinical pathologists (experts), 12 pathology residents (intermediates) and 13 medical students (novices). They diagnosed 10 microscopic images of colon tissue for 2 seconds. Eye movements, the given diagnoses, and the vocabulary used in post hoc verbal explanations were registered. Eye movements were analysed according to changes over trial time and the processing of diagnostically relevant areas. The content analysis of verbal data was based on a categorisation system developed from the literature.

RESULTS Although experts and intermediates showed equal levels of diagnostic accuracy, their visual and cognitive processing differed.
Whereas experts relied on their first findings and checked the image further for other abnormalities, intermediates tended to double-check their first findings. In their explanations, experts focused on the typicality of the tissue, whereas intermediates mainly mentioned many specific pathologies. Novices looked less often at the relevant areas and were incomplete, incorrect and inconclusive in their explanations. Their diagnostic accuracy was correspondingly poor.

CONCLUSIONS This study indicates that in the case of intermediates and experts, different visual and cognitive strategies can result in equal levels of diagnostic accuracy. Lessons for training underline the relevance of the distinction between normal and abnormal tissue for novices, especially when the mental rotation of 2-D images is required. Intermediates need to be trained to see deviations in abnormalities. Feedback and an educational design that is specific to these developmental stages might improve training.

\footnotetext{
${ }^{1}$ Centre for Learning Sciences and Technologies (CELSTEC), Open Universiteit in The Netherlands, Heerlen, The Netherlands ${ }^{2}$ Department of Pathology, Atrium Medical Centre, Heerlen, The Netherlands

${ }^{3}$ Department of Educational Development and Research, Faculty of Health, Medicine and Life Sciences, Maastricht University, Maastricht, The Netherlands
}

Correspondence: Thomas Jaarsma, Centre for Learning Sciences and Technologies (CELSTEC), Open University of The Netherlands, PO Box 2960, 6401 DL Heerlen, The Netherlands. Tel: 003145576 2493; E-mail: thomas.jaarsma@ou.nl 


\section{INTRODUCTION}

The obvious goal of training in clinical pathology is to turn medical students into capable diagnosticians. It is less obvious which stages trainees go through and, hence, which training methods are most appropriate to these stages. This study forms a basis for later explorations of improvements in education. Its central question is: What are the differences among practitioners with different levels of expertise in clinical pathology, namely, medical students, residents and pathologists? Although this is not the first study of differences in expertise in this domain, ${ }^{1-3}$ it is the first to combine diagnostic accuracy with visual and cognitive expertise to give a complete account of typical novice, intermediate and expert behaviours.

\section{Recognition and inference}

Lesgold $e t a l .{ }^{4}$ studied the development of expertise in a medical specialty that, like clinical pathology, is heavily reliant on images: radiology. These authors ${ }^{4}$ describe a diagnostic process that consists of two steps: (i) the recognition of relevant features, and (ii) the inferential processing of perceptual findings to select the best-fitting diagnosis. This distinction bears some resemblance to the work of others on intuitive versus analytical decision making, ${ }^{5,6}$ but differs as it is mediated by, and emphasises the role of, knowledge structures. Expertise development essentially consists of the ability to perform the second step, inferential processing. This means that expertise development is equivalent to the acquisition of and the ability to effectively apply schemata, which are dynamic constellations of enabling conditions, faults, consequences and diagnoses (referred to as 'illness scripts' by Feltovich and Barrows ${ }^{7}$ and Charlin et al. ${ }^{8}$ ).

As residents diagnose more cases, they develop 'ever more refined schemata [...] through a cognitively deep form of generalisation and discrimination'. With these refined schemata, expert radiologists are able to recognise patterns, as opposed to separate features, and, through inference, select the best-fitting diagnosis if their perceptual findings lead to a set of alternative diagnoses. In the latter case, the schemata triggered by the first findings are tested and accordingly accepted, tuned or discarded. ${ }^{4}$

\section{Visual and cognitive processing}

The study by Lesgold $e t a{ }^{4}{ }^{4}$ shows that the diagnostic process is both cognitive and visual. Experts are able to apply and test their more refined cognitive schemata because they also have better visual discriminative ability. Therefore, both types of processing (visual and cognitive) are taken up in this study.

Cognitive processing is often measured using verbal protocols. ${ }^{9}$ In the study by Lesgold and colleagues, the protocols of experts showed more and longer reasoning chains (i.e. more inferential thinking), which resulted in a more coherent mental model of the problem, whereas those of novices were fragmented and more superficial. ${ }^{4}$ To measure visual processing, the participants drew and recalled abnormalities in the images. The novices' visual acuity was inferior, and their recalls were less often related to relevant organs. ${ }^{4}$ However, these results do not give a definitive report of what the participants looked at and in what order, or of whether the viewing process included different phases. To record this behaviour, the present study uses an eye tracker, ${ }^{10}$ which is an apparatus that measures the movements of the eyeballs. These eye movements are directed by the viewer and can thus be seen as a manifestation of what is considered by the viewer to be relevant to the diagnosis. ${ }^{11}$

Eye movement studies have reported several differences in viewing behaviour between experienced and less experienced diagnosticians. Often, intermediates appear to be the deviating group ${ }^{1,12-14}$. Additionally, different stages of the diagnostic process have been reported. ${ }^{15,16}$ One of these models includes a global searching phase followed by focal examination of abnormalities, a strategy attributed to experts. ${ }^{16}$

From this overview of previous research, the following research questions are derived: (i) What differences in visual processing can be found among medical students, residents and pathologists? (ii) What differences in cognitive processing can be found among medical students, residents and pathologists? In addition, we measure diagnostic accuracy as a check on differences in expertise.

\section{METHODS}

\section{Participants and design}

Participants $(n=38$; mean \pm standard deviation [SD] age: $35.39 \pm 14.67$ years; 24 women) formed three groups with different levels of expertise. 'Experts' were represented by 13 clinical pathologists (mean \pm SD age: $51.77 \pm 10.05$ years; three 
women) with a mean \pm SD length of experience of $21.38 \pm 10.03$ years, including 5 years of training. 'Intermediates' were 12 residents (mean \pm SD age: $33.25 \pm 6.28$ years; eight women) with a mean $\pm \mathrm{SD}$ training of $3.00 \pm 1.60$ years. 'Novices' were 13 Year two medical students who had undertaken two courses in the physiology and pathology of cells and tissue, including the gastrointestinal tract (mean \pm SD age: $21.00 \pm 2.58$ years; all women). They were not trained specifically in diagnosing histopathological slides.

\section{Materials and apparatus}

Stimuli consisted of 10 digitally scanned microscopic images of colon tissue. All cases were obtained from the Atrium Medical Centre, Heerlen, the Netherlands, and had been diagnosed by four clinical pathologists as adenocarcinomas (cancer), adenomas (pre-stage of cancer) or normal tissue. Half of the images were presented at low magnification (three adenocarcinomas, one adenoma, one normal), and the other half were shown at high magnification (two adenocarcinomas, two adenomas, one normal).

To ensure that the task was challenging, viewing time was restricted to 2 seconds. This was short enough to be difficult for experts, but long enough to offer novices an opportunity to reach the correct diagnosis.

Eye movements were recorded with the SMI RED eye tracker (SensoMotoric Instruments $\mathrm{GmbH}$, Teltow, Germany) at a temporal resolution of $250 \mathrm{~Hz}$.

\section{Procedure}

The experiment was carried out in individual sessions of about 20 minutes in duration. First, participants completed a questionnaire including items on their sex, age, vision and experience with the colon and digital microscope. Next, they performed the Miles test for the dominant eye ${ }^{17}$ and were introduced to the software. The eye tracking system was calibrated for each participant and validated directly afterwards.

The viewing time per image was limited to 2 seconds in order to focus on the initial processing. Other than this limit, the setting simulated the normal working procedure. First, the patient background was presented, including sex, age, type of tissue, and comments from the requesting doctor. The image appeared when the participant pushed a button and disappeared automatically after 2 seconds. The participant then had to select one of five diagnostic categories (the last two were distractors): normal; adenoma; adenocarcinoma; inflammation, and hyperplastic polyp. Immediately afterwards, the participant gave a verbal explanation for his or her choice. This procedure was repeated for each case. The experiment ended with another validation of the eye tracker to control for offset. Participants received a small gift (a book voucher).

\section{Data analysis}

Diagnostic accuracy

Diagnostic accuracy was operationalised as the correctness of the diagnosis (i.e. its correspondence with a predetermined consensus diagnosis). Specifications given in the verbal explanation were not taken into consideration. Data were treated as categorical (numbers of correct and incorrect diagnoses) and the relationship with level of expertise was tested with chi-squared analysis.

\section{Eye tracking data}

Scan path length (sum of the distances between fixations, in pixels) and fixation dispersion (the extent to which participants covered the image by measuring the spread of fixations, in pixels) expressed the 'reach' of the visual examination. Additionally, average fixation duration was included as a measure of depth of processing.

To measure viewing styles, the first and the last half of each trial were analysed separately, resulting in an independent variable called 'trial part'. The same three dependent variables - scan path length, fixation dispersion and average fixation duration were included in this analysis.

Areas of interest (AoIs) were drawn for every image to measure whether participants attended to crucial cues for the correct diagnosis. They were independently drawn by two non-participating expert pathologists and subjected to a consensus procedure. The number of fixations in AoIs was selected as a dependent variable.

All eye tracking data were analysed with multi-level modelling to account for the hierarchy in the data (cross-classified with measurements on the first level, and both participants and images on the second). 
Verbal data

The verbal data (i.e. the post hoc explanations for the diagnoses given by the participants) were analysed based on methods derived from language technologies. ${ }^{18,19}$ All transcribed verbal protocols of each level of expertise were treated as a combined set of transcripts. Pronouns, off-topic adverbs and verbs, and prepositions were left out of the analysis. Next, two judges (the first and last authors) independently grouped the words into categories (Table 1). This process was iterative as the categorisation was derived partially bottom-up from the data and partially top-down from the literature. The categories 'comparatives' and 'descriptives', for example, were based on the study by Lesgold $e t a l .{ }^{4}$ The first category indicates the use of schemata with which to compare the image, and the latter a lack of schemata, in which features are described by their appearance. By identifying and counting the indicative words for each category, this content analysis was specifically sensitive for finding differences in both knowledge and ways of reasoning among the three groups. ${ }^{20,21}$ More specifically, the categories 'reasoning', 'conclusives', 'diagnosis', 'overview' and 'spatial orientation' were created to bring forth differences in reasoning, and the categories 'comparatives', 'descriptives', 'anatomy', 'pathologies' and 'diagnostic specifications' were intended to elucidate differences in knowledge.

The frequencies per expertise level were tested for significance with chi-squared analysis. This analysis was further broken down using Z-statistics to test significance per category.

\section{RESULTS}

\section{Diagnostic accuracy}

Chi-squared analysis showed a significant association between diagnostic accuracy and expertise level $\left(\chi^{2}\right.$ $[2, n=38]=92.35 ; \mathrm{p}<0.001)$. Table 2 shows the percentages of correct diagnoses.

\section{Eye tracking}

The means and SDs of all eye tracking variables are presented in Table 2.

\section{Scan path length}

Expertise level significantly predicted scan path length $\left(F_{2,36.48}=3.56 ; \mathrm{p}=0.04\right)$, which is the sum of all distances between fixations (in pixels). Pairwise comparisons (with Bonferroni correction) of expertise levels revealed significantly shorter scan paths for novices than for intermediates $(p=0.05)$, indicating that novices processed a smaller part of the image than did intermediates. Experts did not differ significantly in this regard from novices $(p=0.15)$ or intermediates $(p=1.00)$.

\section{Fixation dispersion}

Expertise level did not significantly predict fixation dispersion $\left(F_{2,37.03}=0.37 ; \mathrm{p}=0.70\right)$. This result indicates that there were no differences among the groups in the spatial spread of their visual fixations.

Table 1 Category of words for the analysis of verbal data, including a description and examples

\begin{tabular}{|c|c|c|}
\hline Category & Description & Examples (words) \\
\hline Reasoning & Words characteristic of a chain of reasoning & Because, as, so, but \\
\hline Comparatives & Qualifications based on comparisons with mental models & Irregular, normal, increase \\
\hline Conclusives & Words used to come to a conclusion & Diagnosis, characteristic (for) \\
\hline Descriptives & $\begin{array}{l}\text { Terms used to describe features in images in terms of colour } \\
\text { and size }\end{array}$ & Purple, pink, round, flowers \\
\hline Diagnosis & Words referring to a diagnosis & Adenoma, adenocarcinoma \\
\hline Anatomy & Words referring to the anatomy of tissue and cells & Epithelium, nucleus, lamina propria \\
\hline Pathologies & Specific terms referring to an anomaly in the tissue & Lymphocytes, invasion, infiltration \\
\hline Overview & Words referring to an overview of the image and process & Architecture, coupe, patient information \\
\hline Diagnostic specifications & Terms that specify a certain diagnosis & High-grade, infiltrating \\
\hline Spatial orientation & Words referring to the spatial orientation of features in the image & Bottom, left, depth \\
\hline
\end{tabular}


Table 2 Performance of participants: correct diagnoses and means of eye tracking variables by expertise level

\begin{tabular}{|c|c|c|c|c|c|c|c|c|}
\hline & $\begin{array}{l}\text { Correct } \\
\text { diagnoses }\end{array}$ & \multicolumn{2}{|c|}{$\begin{array}{l}\text { Scan path length, } \\
\text { pixels } \\
\text { (mean } \pm \text { SD) }\end{array}$} & \multicolumn{2}{|c|}{$\begin{array}{l}\text { Fixation } \\
\text { dispersion, pixels } \\
\text { (mean } \pm \text { SD) }\end{array}$} & \multicolumn{2}{|c|}{$\begin{array}{l}\text { Average fixation } \\
\text { duration, ms } \\
\text { (mean } \pm \text { SD) }\end{array}$} & $\begin{array}{l}\text { Fixations } \\
\text { in Aols } \\
\text { (mean } \pm S D \text { ) }\end{array}$ \\
\hline Novices & $38.6 \% *, \dagger$ & $903 \pm 80.2^{\dagger}$ & & $279 \pm 27.2$ & & $208 \pm 9.1$ & & $3.0 \pm 0.37^{\dagger}$ \\
\hline Intermediates & $87.5 \%$ & $1089 \pm 81.5$ & & $308 \pm 28.2$ & & $184 \pm 9.4$ & & $3.9 \pm 0.38$ \\
\hline Experts & $85.4 \%$ & $1054 \pm 81.4$ & & $279 \pm 28.2$ & & $197 \pm 9.4$ & & $3.6 \pm 0.38$ \\
\hline $\begin{array}{c}\text { Analyses per } \\
\text { trial part }\end{array}$ & & 1 & 2 & 1 & 2 & 1 & 2 & \\
\hline Novices & & $358 \pm 38.0$ & $418 \pm 37.8$ & $157 \pm 16.3$ & $143 \pm 16.2$ & $240 \pm 10.4$ & $213 \pm 11.0$ & \\
\hline Intermediates & & $436 \pm 38.7$ & $520 \pm 38.6$ & $192 \pm 16.9$ & $165 \pm 16.8^{\ddagger}$ & $218 \pm 10.7$ & $194 \pm 11.2^{*}$ & \\
\hline Experts & & $392 \pm 38.6$ & $519 \pm 38.6$ & $135 \pm 16.9$ & $167 \pm 16.8^{\ddagger}$ & $243 \pm 10.8$ & $191 \pm 11.2^{*}$ & \\
\hline
\end{tabular}

* Three diagnoses of novices were missing, giving a total of 127 rather than 130 .

$\dagger$ Significantly different $(p<0.05)$ from other two expertise levels.

$\$$ Significantly different $(p<0.05)$ from first trial part (same expertise level).

ms, milliseconds; SD, standard deviation; Aol, area of interest.

\section{Average fixation duration}

Expertise level did not significantly affect the average amount of time that eye gaze was fixed at any given point $\left(F_{2,36.91}=1.78 ; \mathrm{p}=0.18\right)$.

\section{Viewing styles}

Trial part (i.e. the early versus the late intervals of each trial) significantly predicted scan path length $\left(F_{1,685.06}=34.13 ; \mathrm{p}<0.001\right)$ such that the scan path length in all three groups was significantly longer in the second part than in the first $(p<0.001)$. The interaction between expertise level and trial part was not significant $\left(F_{2,685.04}=1.66 ; \mathrm{p}=0.19\right)$.

For fixation dispersion, trial part was not a significant predictor $\left(F_{1,685.19}=0.14 ; \mathrm{p}=0.71\right)$. However, the interaction of trial part and expertise was significant $\left(F_{1,685.16}=7.18 ; \mathrm{p}<0.001\right)$. Figure 1 shows that this interaction was caused by the larger dispersion in the second trial part for experts and the smaller dispersion in the second trial part for intermediates. This means that the experts' fixations were more concentrated in the first part of the trial, compared with the second. Those of intermediates were more spread out in the first half and closer to one another in the second.

Trial part significantly predicted fixation duration $\left(F_{1,2224.06}=63.50 ; \mathrm{p}<0.001\right)$ such that fixation durations in the first trial part were significantly longer than those in the second part $(p<0.001)$. The interaction of expertise level and trial part was also significant $\left(F_{2,2224.99}=4.07 ; \mathrm{p}=0.02\right)$. Figure 1 shows that this interaction effect was mainly caused by the experts having the longest fixation duration in trial part 1 , and the shortest in trial part 2.

\section{Diagnostically relevant areas}

Expertise level significantly predicted the number of fixations in the AoIs $\left(F_{2,35.79}=5.81 ; \mathrm{p}=0.01\right)$. Pairwise comparisons (with Bonferroni correction) showed significantly fewer fixations for novices than for intermediates $(p=0.01)$ and marginally significantly fewer fixations for novices than for experts $(p=0.06)$. Intermediates and experts did not differ significantly $(p=1.00)$. Intermediates and experts thus looked equally often at diagnostically relevant areas, whereas novices looked at them less often.

\section{Verbal data}

There was a significant association between expertise level and the frequency of words in certain categories $\left(\chi^{2}[22, n=3007]=418 ; \mathrm{p}<0.001\right)$ (Fig. 2).

Novices used many words indicative of reasoning $(n=343)$, descriptions $(n=52)$ and diagnostic terms $(n=190)$. However, they mentioned few pathologies $(n=53)$ and few conclusive terms 

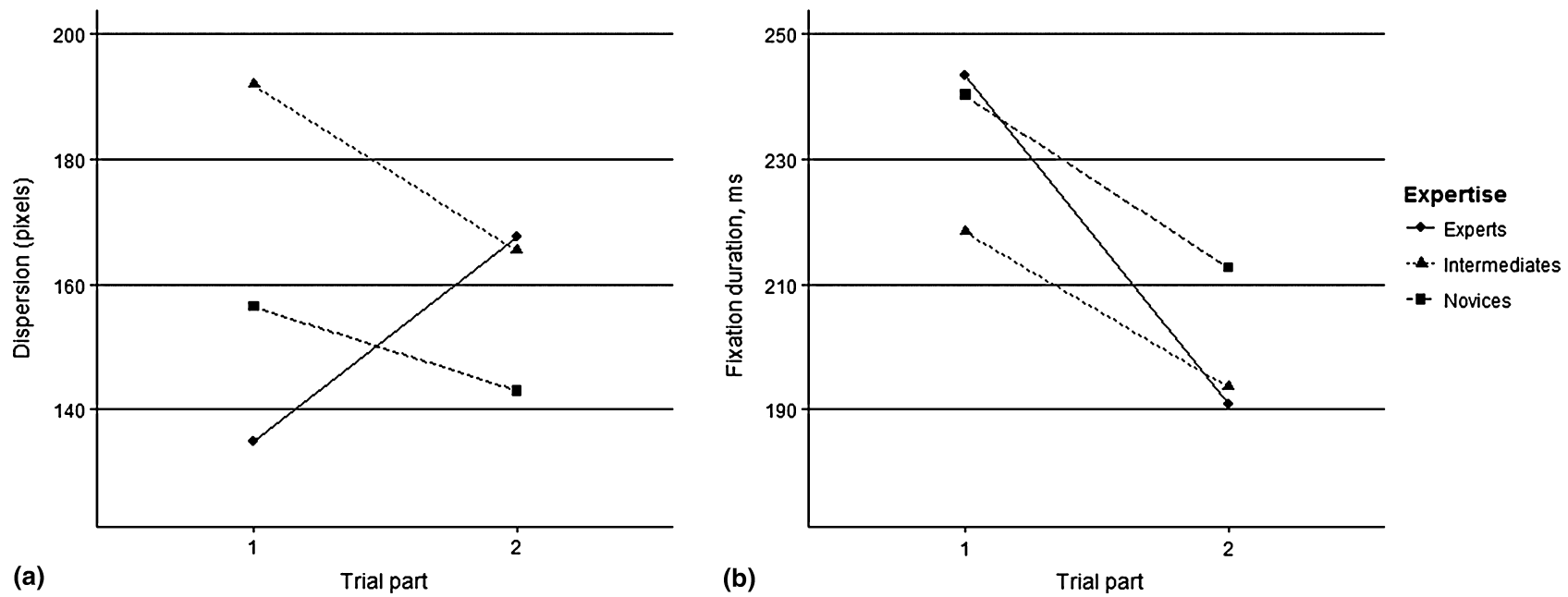

Figure 1 Interaction effects for (a) dispersion and trial part, and (b) fixation duration and trial part. ms, milliseconds

$(n=5)$. These frequencies indicate that a typical novice protocol is a long, inconclusive chain of reasoning, based on descriptions rather than identified pathologies, and considers all diagnostic options.

Experts used many words that indicated comparisons with schemata (i.e. comparatives, $n=194$ ), as well as words used to obtain an overview $(n=67)$ and diagnostic specifications $(n=26)$. They used

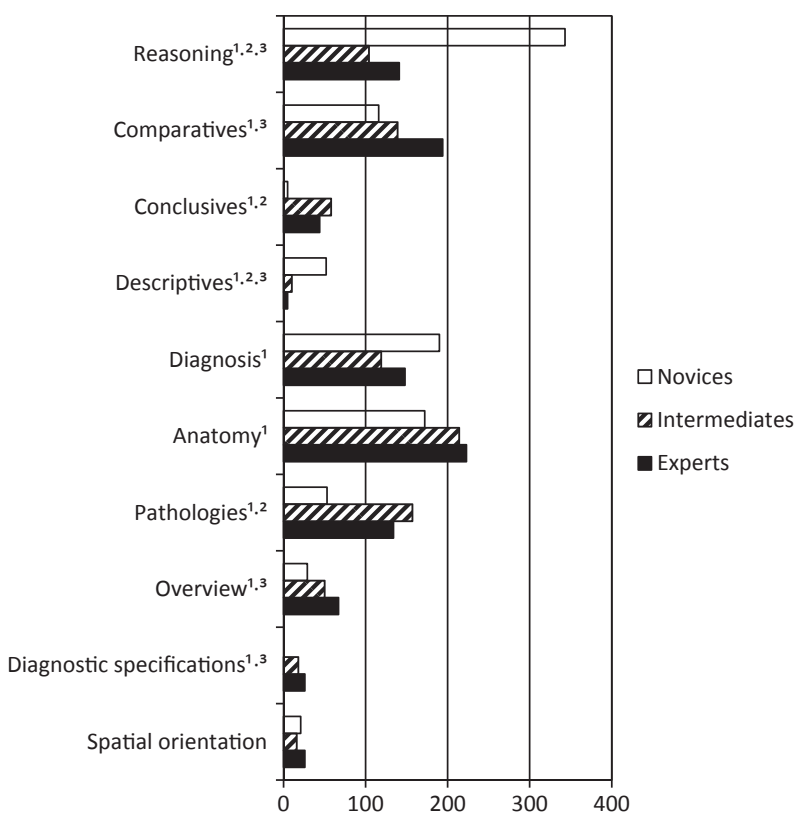

Figure 2 Frequencies by coding category and expertise level. ${ }^{1}$ The frequency of novices differs significantly from the expected value; ${ }^{2}$ the frequency of intermediates differs significantly from the expected value; ${ }^{3}$ the frequency of experts differs significantly from the expected value fewer words on pathologies $(n=134)$ and conclusions $(n=44)$ than intermediates. These frequencies indicate a typical expert protocol, which, although to a lesser degree than that of intermediates, contains many specific pathologies, as well as relatively many terms that indicate comparisons with normal situations and typical presentations of disease. Moreover, experts' protocols indicate that they create an overview using anatomical terms and come to more specified diagnoses.

The intermediates' protocol resembled that of experts on anatomy terms $(n=214)$, but contained fewer comparatives $(n=139)$ and mentioned more specific pathologies $(n=157)$. In general, their content resembled that of experts more than that of novices. These frequencies indicate that intermediates verbalise their findings in terms of specific pathologies more than by using implicit comparisons with normal tissue (e.g. '[a]typical').

Table 3 shows illustrations of the protocols by expertise level.

\section{DISCUSSION}

\section{Diagnostic accuracy by expertise level}

In this experiment, intermediates and experts scored equally highly $(87.5 \%$ and $85.4 \%$, respectively), making differentiation difficult. The measure used here was rather coarse: participants were asked to categorise the case (i.e. to choose one of five diagnostic categories), rather than to give a specific 
Table 3 Illustrative protocols for each of the levels (protocols are taken up integrally)

\begin{tabular}{|c|c|c|c|}
\hline Participant & Expert_05 & Intermediate_02 & Novice_07 \\
\hline Case & 9 & 10 & 3 \\
\hline Diagnosis & Adenocarcinoma & Adenoma & Adenoma \\
\hline Protocol & $\begin{array}{l}\text { 'Colon biopsies }{ }^{8} \text { with densely oriented } \\
\text { tubes }^{6}, \text { some of them severely } \\
\text { atypical }^{2} \text {. They seem to be surrounded } \\
\text { by a stromal response }{ }^{7} \text {. Lots of } \\
\text { inflammation'. At first sight, this is } \\
\text { an invasive }{ }^{9} \text { adenocarcinoma }{ }^{5} \text {. An } \\
\text { inflammation }{ }^{5} \text { with an extended } \\
\text { reactive change cannot be excluded } \\
\text { at this stage' }\end{array}$ & $\begin{array}{l}\text { 'Increased mitosis, proliferation }{ }^{7} \text { of } \\
\text { colon epithelium }^{6} \text {. The tubes }{ }^{6} \text { are still } \\
\text { orderly placed, parallel. No invasion }{ }^{7} \text { into } \\
\text { the stroma', not suspect }{ }^{3} \text { for malignancy. } \\
{\text { Could } \text { fit }^{3} \text { an adenoma }}^{5} \text {. Or a } \\
\text { hyperplastic polyp }\end{array}$ & $\begin{array}{l}\text { 'Okay, I think I would go for a } \\
\text { hyperplastic polyp }{ }^{5} \text { here, because } \\
\text { somewhere I saw a lot of... well, } \\
\text { kind of villous humps, where a } \\
\text { lot of, with a very thick layer of a } \\
\text { pinkish }{ }^{4} \text { substance. So }{ }^{1} \text { if there is } \\
\text { that much mucus being produced, } \\
\text { then I think it could very well be } \\
\text { hyperplastic }{ }^{5} \text {. But }{ }^{1} \text { I didn't see } \\
\text { such a number of tubuli }{ }^{6} \text { that I } \\
\text { would say: this is an adenoma }{ }^{5} \text {. } \\
\text { So }{ }^{7} \text { then hyperplastic }{ }^{5} \text {, }\end{array}$ \\
\hline
\end{tabular}

diagnosis, which allows little variability at the high end of the scale. Nuances in the verbal protocols of experts (i.e. many diagnostic specifications) suggest that more finely grained indicators might be able to differentiate among the groups.

\section{What differences in visual processing emerged among medical students, residents and pathologists?}

Compared with intermediates and experts, novices processed smaller parts of the image and fixated less often on relevant parts. The latter finding indicates that novices had trouble recognising these relevant parts, which may be explained by their status as Year 2 medical students who are not yet very familiar with histological images. Not only did the novices in the present study fail to recognise abnormalities, but they often did not recognise normal colon tissue either. Images of colon tissue presented during their pathology courses were cross-sections presented at an angle that is optimal for demonstrating the structure of tissue, but differs from the angle used in the images in this experiment (and, hence, in practice). As a result, novices failed to translate one type of image into the other. The elementary role of visual spatial ability in microscopy has also been shown by Helle $e t a l .^{22}$ in early stages of learning.
Experts and intermediates performed similarly on all eye tracking variables, except one: fixation dispersion of separate trial parts. The intermediates' fixation dispersion decreased in the second trial part, whereas that of experts increased. Intermediates seemed to recheck the part they had examined earlier, whereas experts explored new parts. Apparently, each group used a different viewing strategy, but both demonstrated equal diagnostic accuracy.

This result aligns with the conclusions of the study by Lesgold et al. ${ }^{4}$ The relatively small fixations dispersion of experts in the first trial part might be caused by the patient background information: this triggers a schema that guides the expert's viewing. After quick recognition of the relevant patterns, the rest of the image is scanned for anything that contradicts the schema. Intermediates are in the process of acquiring these schemata and are apparently tempted to recheck their findings.

\section{What differences in cognitive processing emerged among medical students, residents and pathologists?}

In their explanations derived from the verbal data, novices used many reasoning, descriptive and diagnosistic words. Typically, novices thus considered many diagnostic options, connecting their argu- 
ments with words such as 'but' and 'because'. The arguments put forward in these lines of reasoning often involved perceptions (colours, shapes) and less often specific pathologies or anatomy terms. Many of these considerations were inconclusive: the diagnoses were eventually based on haphazard decisions. Such a protocol matches the inability to recognise relevant features, and indicates that novices do not yet possess schemata that direct their thinking.

A typical explanation from an intermediate contained many pathologies and conclusive words. Compared with novices, intermediates thus reasoned less, detected more pathologies and were conclusive. Their conclusions were based on 'labelled findings': these were specific pathologies that were found in the images and verbalised as such. The fact that intermediates mentioned the highest number of pathologies corresponds with the superior extent of pathological explanations given by intermediates and highlighted by Boshuizen and Schmidt. ${ }^{23-25}$

By contrast with the 'labelling' of intermediates, experts used more comparative terms, such as 'typical', 'regular' and 'increase of', to verbalise their findings. This may indicate either of two things: (i) experts summarise several findings with one qualification, and (ii) experts compare the image with a referential mental image or a triggered schema. Additionally, experts' protocols contained many overview terms, indicating an ability to distance themselves from the image and reflect, and many diagnostic specifications, indicating the presence of more refined schemata.

\section{Lessons for training}

An obstacle for novices is the mental rotation of 2-D images. As a result, they fail to recognise the tissue on display. This skill can be trained specifically, for example by linking 2-D images with different angles to the 3-D organ. Additionally, novices seem to have trouble in distinguishing between normal and abnormal tissue, also a skill that can be trained specifically. Intermediates perform similarly to experts, but their visual strategies and vocabulary differ. The most important difference between these two groups lies in the search-then-detect approach of intermediates, as opposed to the recognise/ detect-then-search approach of experts. ${ }^{2,26}$ Although specific training lessons are difficult to deduce from these results, feedback seems to play a role in the gaining of expertise: radiology residents trained with feedback loops were reported to perform better than those who simply read a high volume of cases. $^{26}$

\section{Limitations and future research}

Participants in this study were given 2 seconds to reach a diagnosis. Restricting viewing time is an often-used method in perception research ${ }^{27}$ and offers the opportunity to focus on the very first processes to take place in the visual system. Moreover, using a standardised task helps to identify recurring patterns that characterise expert behaviour, the main goal of expertise research. However, this prevented our inclusion of certain aspects of pathology expertise, such as microscope use. As this study represents a first attempt to investigate expertise in pathology (using a combination of eye tracking and verbal data), it may serve as a basis for future investigations in more naturalistic settings. A second limitation is that content analysis is an efficient but superficial method of analysing verbal data. ${ }^{28}$ Although it is informative in the analysis of post hoc explanations, more in-depth analyses are required when cognitive and visual processing data are analysed in an integrative way. ${ }^{29}$ Lastly, this study gives insights into differences in expertise, but not into effective training methods. This would be an interesting topic for future research, which might, for example, be conducted by including an intervention that impacts on how residents in clinical pathology are trained.

Contributors: TJ contributed to the study design, recorded the data, performed the data analysis, contributed to the theoretical framework and wrote the first draft of the manuscript. HJ contributed to the study design, the analysis of eye tracking data and the theoretical framework. MN contributed to the study design and participated as a domain-specific consultant. JJGvM contributed to the study design and the theoretical framework. HPAB contributed to the study design, the analysis of verbal data and the theoretical framework. All authors contributed to the writing and revision of the paper and approved the final manuscript.

Acknowledgements: the authors would like to thank the participants in this study and especially Professor Dr J G van den Tweel, Department of Pathology, UMC Utrecht, Utrecht, The Netherlands, and Professor Dr P van der Valk, Department of Pathology, VU University Medical Center, Amsterdam, The Netherlands, for their cooperation in data recording, and Professor Dr H van den Bergh, Utrecht Institute of Linguistucs OTS, Utrecht University, Utrecht, The Netherlands, for his help with statistical analyses.

Funding: no external funding was received. The costs of the study were covered by internal funding. 
Conflicts of interest: none.

Ethical approval: this study was reviewed by the ethics committee of the Open University of the Netherlands (Open Universiteit Nederland) and deemed not to require formal medical ethics approval.

\section{REFERENCES}

1 Krupinski EA, Tillack AA, Richter L, Henderson JT, Bhattacharyya AK, Scott KM, Graham AR, Descour MR, Davis JR, Weinstein RS. Eye-movement study and human performance using telepathology virtual slides: implications for medical education and differences with experience. Hum Pathol 2006;37:1543-56.

2 Mello-Thoms C, Mello CAB, Medvedeva O, Castine M, Legowski E, Gardner G, Tseytlin E, Crowley R. Perceptual analysis of the reading of dermatopathology virtual slides by pathology residents. Arch Pathol Lab Med 2012;136:551-62.

3 Crowley RS, Naus GJ, Stewart J, Friedman CP. Development of visual diagnostic expertise in pathology - an information-processing study. $\mathrm{J} \mathrm{Am}$ Med Inform Assoc 2003;10:39-51.

4 Lesgold A, Rubinson H, Feltovich P, Glaser R, Klopfer D, Wang Y. Expertise in a complex skill: diagnosing X-ray pictures. In: Chi MTH, Glaser R, Farr M, eds. The Nature of Expertise. Hillsdale, NJ: Lawrence Erlbaum Associates 1988;311-42.

5 Kahneman D, Klein G. Conditions for intuitive expertise: a failure to disagree. Am Psychol 2009;64: 515-26.

6 Croskerry P. A universal model of diagnostic reasoning. Acad Med 2009;84:1022-8.

7 Feltovich PJ, Barrows HS. Issues of generality in medical problem solving. In: Schmidt HG, De Volder ML, eds. Tutorials in Problem-Based Learning. Assen: Van Gorcum 1984;128-42.

8 Charlin B, Boshuizen HPA, Custers EJ, Feltovich PJ. Scripts and clinical reasoning. Med Educ 2007;41: 1178-84.

9 Ericsson KA, Simon HA. Verbal reports as data. Psychol Rev 1980;87:215-51.

10 Holmqvist K, Nyström M, Andersson R, Dewhurst R, Jarodzka H, van de Weijer J. Eye Tracking: A Comprehensive Guide to Methods and Measures. Oxford: Oxford University Press 2011. Chapter 2, Eyetracker and its Properties, 51-64.

11 Just MA, Carpenter PA. Eye fixations and cognitive processes. Cogn Psychol 1976;8:441-80.

12 Cooper L, Gale A, Darker I, Toms A, Saada J, eds. Radiology image perception and observer performance: how does expertise and clinical information alter interpretation? Stroke detection explored through eye-tracking. Proceedings of SPIE Medical Imaging, 7-12 February 2009, Lake Buena Vista, FL.

13 Cooper L, Gale A, Saada J, Gedela S, Scott H, Toms A, eds. The assessment of stroke multidimensional CT and MR imaging using eye movement analysis: does modality preference enhance observer performance? Proceedings of SPIE Medical Imaging, 13-18 February 2010, San Diego, CA.

14 Donovan T, Damien L. Looking for cancer: expertiserelated differences in searching and decision making. Appl Cogn Psychol 2013;27:43-9.

15 Swensson R. A two-stage detection model applied to skilled visual search by radiologists. Percept Psychophys 1980;27:11-6.

16 Kundel HL, Nodine CF, Carmody D. Visual scanning, pattern recognition and decision making in pulmonary nodule detection. Investig Radiol 1978;13:175-81.

17 Miles WR. Ocular dominance in human adults. J Gen Psychol 1930;3:412-30.

18 Berlanga AJ, van Rosmalen P, Boshuizen HPA, Sloep PB. Exploring formative feedback on textual assignments with the help of automatically created visual representations. J Comput Assist Learn 2012;28:146-60.

19 Chung CK, Pennebaker JW. The psychological function of function words. In: Fiedler K, ed. Social Communication: Frontiers of Social Psychology. New York, NY: Psychology Press 2007;343-59.

20 Jordan S. Learning to be surprised: how to foster reflective practice in a high-reliability context. Manage Learn 2010;41:391-413.

21 Bruno A, Galuppo L, Gilardi S. Evaluating the reflexive practices in a learning experience. Eur J Psychol Educ 2011;26:527-43.

22 Helle L, Nivala M, Kronqvist P, Ericsson KA, Lehtinen E. Do prior knowledge, personality and visual perceptual ability predict student performance in microscopic pathology? Med Educ 2010;44:621-9.

23 Boshuizen HPA, Schmidt HG. On the role of biomedical knowledge in clinical reasoning by experts, intermediates and novices. Cognit Sci 1992;16:153-84.

24 Schmidt H, Boshuizen H. On the origin of intermediate effects in clinical case recall. Mem Cognit 1993;21: 338-51.

25 Schmidt HG, Boshuizen HPA. On acquiring expertise in medicine. Educ Psychol Rev 1993;5:205-21.

26 Nodine CF, Mello-Thoms C. The role of expertise in radiologic image perception. In: Samei E, Krupinski EA, eds. Medical Image Perception and Techniques. New York, NY: Cambridge University Press 2010;139-56.

27 Reingold EM, Sheridan H. Eye movements and visual expertise in chess and medicine. In: Liversedge S, Gilchrist I, Everling S, eds. Oxford Handbook of Eye Movements. New York, NY: Oxford University Press 2011;523-50.

28 Malterud K. Qualitative research: standards, challenges, and guidelines. Lancet 2001;358:483-88.

29 van Someren MW, Barnard YF, Sandberg JAC. The Think Aloud Method. London: Academic Press 1994. Chapter 2, Studying the content of cognitive processes, 13-26.

Received 15 May 2013; editorial comments to author 27 June 2013, 12 August 2013; accepted for publication 18 September 2013 